\title{
ENFRENTAMENTO, ASPECTOS CLÍNICOS E SOCIODEMOGRÁFICOS DE PESSOAS VIVENDO COM HIV/AIDS
}

\author{
Eliane Maria Fleury Seidl
}

\begin{abstract}
RESUMO. O estudo objetivou descrever as estratégias de enfrentamento adotadas por pessoas portadoras de HIV/Aids e identificar associações entre modalidades de enfrentamento e variáveis sociodemográficas (sexo, escolaridade e situação conjugal) e médico-clínica (condição sintomática e assintomática). A amostra de conveniência foi composta de 241 pessoas soropositivas, $161(66,8 \%)$ homens, de 20 a 64 anos $(M=37,4 ; D P=7,8), 169$ (70,1\%) sintomáticas. A coleta de dados incluiu questionários estruturados e a Escala Modos de Enfrentamento de Problemas (EMEP), com aplicação individual assistida e preenchimento da EMEP sem a presença do pesquisador. Os resultados indicaram a variabilidade das estratégias de enfrentamento, com predomínio de enfrentamento focalizado no problema. Em mulheres e pessoas com níveis mais baixos de escolaridade predominaram enfrentamento focalizado na emoção e busca de práticas religiosas. Os resultados fornecem subsídios para a intervenção psicológica em se tratando de pessoas soropositivas. Limitações da conceituação e da avaliação do enfrentamento são discutidas, devendo ser consideradas em estudos futuros.
\end{abstract}

Palavras-chave: enfrentamento e aspectos sociodemográficos, HIV/Aids, psicologia da saúde.

\section{COPING, CLINICAL AND SOCIODEMOGRAPHIC ASPECTS OF PEOPLE LIVING WITH HIV/AIDS}

\begin{abstract}
The study aimed at describing coping strategies of people living with HIV/AIDS and identifying associations between modalities of coping and sociodemographic variables such as sex, schooling and marital status, as well as clinical ones (symptomatic versus asymptomatic conditions). A convenience sample was composed with $241 \mathrm{HIV}+$ people, 161 $(66,8 \%)$ were men between the ages of 20 and $64(\underline{M}=37,4), 169(70,1 \%)$ symptomatic. The instruments used included structured questionnaires and a Brazilian version of a scale for measure strategies of coping, with assisted application and fulfilling of scale without the presence of researchers. Results showed variability in the coping strategies used, with predomination of problem-focused coping. Amongst women and less educated individuals there was a prevalence of emotionfocused coping and search for religious practices. The results provide subsidy for HIV-positive patients to draw sustenance from psychological support. Limitations of conceptualization and evaluation of coping are discussed and must be taken into consideration for future reference in further research.
\end{abstract}

Key words: coping and sociodemographic aspects, HIV/AIDS, health psychology.

O construto enfrentamento tem despertado grande interesse na literatura psicológica (Hobfall, 2002; Thoits, 1995). No modelo interativo do estresse (stress transactional model), enfrentamento "refere-se aos esforços cognitivos e comportamentais voltados para o manejo de demandas externas ou internas, que são avaliadas como sobrecarga aos recursos pessoais" (Folkman, Lazarus, Gruen \& De Longis, 1986, p. 572). Nesse modelo, determinado evento ou situação não é estressante per se: é relevante a avaliação (appraisal) da pessoa quanto ao caráter estressor do evento ou situação. Assim, a mediação cognitiva influencia o processo de enfrentamento. Outro aspecto é que respostas aprendidas e habituais do repertório comportamental do indivíduo muitas vezes não são adequadas e suficientes para lidar com a nova situação, percebida como dano, ameaça ou desafio (Antoniazzi, Dell' Aglio \& Bandeira, 1998).

No campo da saúde, a profusão de pesquisas sobre enfrentamento, principalmente a partir dos anos 1980, tem permitido a produção de conhecimento sobre o tema e o desenvolvimento de intervenções junto a pessoas acometidas por agravos diversos, em especial enfermidades crônicas. Pesquisas sobre estratégias de enfrentamento em contextos de saúde e doença têm valorizado a análise do padrão e/ou

* Doutora em Psicologia pela Universidade de Brasília. Docente da Universidade de Brasília. 
repertório de enfrentamento, bem como a identificação de aspectos sociodemográficos, médico-clínicos e psicológicos associados à utilização de estratégias de enfrentamento (Endler \& Parker, 1999; Seidl, Tróccoli \& Zannon, 2001).

O diagnóstico de infecção pelo HIV tem implicações médicas, psicológicas e sociais significativas, impondo esforços adaptativos relevantes às pessoas soropositivas. Ainda sem cura, a aids hoje tem tratamento e possibilidades efetivas de controle, o que traz novos desafios para os pacientes e profissionais de saúde que trabalham nessa área. As intervenções para promover o enfrentamento à luz dos avanços da terapia anti-retroviral, o fortalecimento do suporte social, a vivência plena da sexualidade, a adesão ao tratamento e a concretização dos projetos de vida são alguns dos tópicos de interesse diante da perspectiva de uma vida longa e com qualidade das pessoas soropositivas (Kelly, Otto-Salaj, Sikemma, Pinkerton \& Bloom, 1998; Wu, 2000).

É possível identificar a mudança de enfoque nos estudos sobre enfrentamento em HIV/aids, desde o período em que a enfermidade não tinha tratamento eficaz e possuía índices elevados de letalidade, até à segunda metade dos anos 1990, quando a terapia antiretroviral combinada foi disponibilizada. Nota-se que o foco dos estudos, a princípio excessivamente direcionado para a incidência de transtornos mentais em pessoas soropositivas, começou a deslocar-se para a identificação dos fatores que propiciam o crescimento psicológico, o ajustamento à condição de enfermidade crônica, o enfrentamento diante da disponibilidade de tratamento e a qualidade de vida das pessoas que vivem com HIV/aids.

Estudo como o de Leserman, Perkins e Evans (1992) ilustram o primeiro momento. Eles pesquisaram as relações entre estratégias de enfrentamento, apoio social, auto-estima e sintomas depressivos em uma amostra de homossexuais masculinos, a maior parte soropositivos assintomáticos. Os autores partiram da hipótese de que estratégias como planejamento, busca de apoio social, espírito de luta - estratégias focalizadas no problema estariam associadas a afeto positivo e auto-estima; por outro lado, negação e desamparo estariam relacionadas à ansiedade e baixa auto-estima. Os resultados mostraram escores altos nas medidas de depressão, com 9,6\% dos participantes apresentando sintomas de depressão grave. A resposta de desamparo para lidar com a aids esteve consistentemente associada à depressão e à baixa auto-estima, e enfrentamento de negação relacionou-se com estados emocionais disfóricos, sobretudo reações de raiva. A satisfação com o apoio social e a participação em organizações não-governamentais estiveram relacionadas a estratégias de enfrentamento mais adaptativas, como reavaliação positiva e espírito de luta.

Fleishman e Fogel (1994) examinaram o enfrentamento de pessoas HIV positivas sintomáticas $(n=736) \quad$ com situações sociodemográficas diversificadas. Um dos objetivos foi verificar se gênero, raça e modo de transmissão estariam relacionados a determinadas estratégias de enfrentamento, bem como investigar a presença de transtornos mentais. A prevalência de sintomas relacionados à depressão atingiu 43,6\% da amostra, sendo maior entre as mulheres, os hispânicos e os usuários de drogas injetáveis. Esquiva como estratégia de enfrentamento foi prevalente entre pessoas de grupos sociais desfavorecidos: não-brancos, usuários de drogas injetáveis e de baixa renda. $\mathrm{O}$ enfrentamento ativo esteve negativamente correlacionado com sintomas depressivos. A elevada prevalência de depressão encontrada foi atribuída pelos autores ao fato de a amostra ser composta por doentes de aids, e não por pessoas HIV+ assintomáticas, em momento no qual não havia tratamento eficaz para essa enfermidade.

Estudos pós-advento da terapia anti-retroviral combinada exemplificam a outra tendência da produção do conhecimento sobre enfrentamento em HIV/aids. Dunbar, Mueller, Medina e Wolf (1998), em estudo com metodologia qualitativa, entrevistaram 34 mulheres norte-americanas $\mathrm{HIV+}$, a fim de investigar como elas transformaram suas vidas em uma direção positiva e produtiva, investigando as características do enfrentamento. Os resultados evidenciaram que os principais componentes foram afirmação da vida, criação de significado, autoafirmação e redefinição dos relacionamentos. A afirmação da vida referiu-se ao momento - superada a idéia da inevitabilidade da morte - caracterizado pelo surgimento de esperança e de vontade de viver. A criação de significado reportou-se à descoberta de um novo sentido para a vida, como a busca de propósitos e a retomada de projetos pessoais. A auto-afirmação, por seu turno, foi descrita como um sentido positivo, com a oportunidade de cuidarem mais de si próprias, diferente das situações em que estavam voltadas apenas para o cuidado de outras pessoas (companheiros e filhos). A redefinição de relacionamentos referiu-se à tentativa de resolver $\mathrm{e}$ clarificar algumas relações pessoais com parceiros, familiares e amigos, pautando-se em critérios de franqueza, honestidade e ética. Os autores concluíram 
que essas mulheres relataram crescimento psicológico e espiritual, sendo que muitas disseram que a capacidade de lidar com o HIV foi facilitada pelas experiências anteriores de enfrentamento de situações difíceis.

As relações entre suporte social, enfrentamento e sofrimento psíquico foram examinadas em amostra de 212 pessoas com HIV/aids (Schmitz \& Crystal, 2000). No modelo analisado, o enfrentamento teria um papel de mediação entre o suporte social e a variável sofrimento psíquico. Os resultados mostraram a presença de efeitos significativos sobre o sofrimento psíquico das variáveis enfrentamento de esquiva, rejeição pela família, gravidade dos sintomas da enfermidade, sentir-se amado e compreendido e suporte social. Sentir-se amado e compreendido mediou a satisfação com o suporte social e foi um preditor importante tanto do enfrentamento ativo quanto do enfrentamento de esquiva (preditor negativo). Propostas de intervenção psicológica visando ao fortalecimento da rede de suporte social e modificação das estratégias de enfrentamento foram apresentadas pelos autores. Os achados desses dois últimos estudos vão ao encontro de tendências mais atuais da literatura sobre estresse e enfrentamento, que reforçam a importância de se pesquisarem as relações entre enfrentamento e afeto positivo (Folkman \& Moskowitz, 2000; Somerfield \& McCrae, 2000).

Os estudos examinados referem-se a populações de outros países, com perfil epidemiológico distinto do brasileiro, caracterizado pelas tendências de feminização e pauperização da epidemia (Ministério da Saúde, 2003). Devido ao aumento do número de casos de aids entre mulheres e pessoas em condições socioeconômicas precárias no país, estudos com amostras diversificadas do ponto de vista sociodemográfico são relevantes para identificar especificidades associadas às estratégias de enfrentamento entre pessoas soropositivas. Os objetivos do presente estudo, parte de uma pesquisa maior sobre qualidade de vida, enfrentamento e suporte social (Seidl, Zannon \& Tróccoli, no prelo), foram descrever as estratégias de enfrentamento de pessoas vivendo com HIV/aids e identificar associações entre modos de enfrentamento e variáveis sociodemográficas (sexo, escolaridade e situação conjugal) e médico-clínicas (condição sintomática versus assintomática).

\section{MÉTODO}

\section{Participantes}

A amostra foi composta de 241 pacientes soropositivos, $161(66,8 \%)$ do sexo masculino, em acompanhamento ambulatorial em dois serviços públicos de saúde do Distrito Federal. A idade variou de 20 a 64 anos $(M=37,4 ; D P=7,8)$. Quanto à escolaridade, $33,6 \%$ dos participantes tinham até o ensino fundamental completo, $35,7 \%$ estudaram até o ensino médio completo, $12,9 \%$ tinham o curso superior incompleto e $17,8 \%$ o superior completo.

No que concerne à situação conjugal, 41,9\% estavam casados ou vivendo em união consensual e mais da metade dos participantes $(58,1 \%)$ não estava vivendo com parceiro/a. Cento e quarenta pessoas $(58,1 \%)$ referiram orientação heterossexual, 77 (32\%) informaram orientação homossexual, 20 homens $(8,3 \%)$ referiram orientação bissexual. Das 140 pessoas com orientação heterossexual, 63 eram do sexo masculino ( $39,1 \%$ do total de homens) e 77 eram do sexo feminino $(96,2 \%$ do total de mulheres). Os percentuais de pessoas heterossexuais vivendo sós $(49,2 \%)$ ou com parceiro $(59,3 \%)$ foram próximos. Quanto às pessoas homossexuais e bissexuais, o maior percentual foi daqueles que não viviam com parceiro/a $(69,7 \%)$, enquanto um terço $(30,3 \%)$ vivia com parceiro/a.

Quanto à situação empregatícia, 31,5\% estavam empregados com direitos trabalhistas, $13,7 \%$ possuíam atividade autônoma regular. $\mathrm{O}$ percentual de desempregados foi de $12,9 \%$ e de aposentados alcançou 47 pessoas $(19,5 \%)$.

\section{Caracterização médico-clínica}

Setenta e duas pessoas $(29,9 \%)$ eram assintomáticas e $169(70,1 \%)$ eram sintomáticas/doentes de aids. Esses dois grupos de pacientes não se diferenciaram quanto ao sexo $\left(\chi^{2}[1, N=241]=0,86 ; p=0,35\right)$, escolaridade $\left(\chi^{2}[1\right.$, $N=241]=2,58 ; p=0,11)$ e situação conjugal $\left(\chi^{2}[1\right.$, $N=241]=1,12 ; p=0,55)$.

O tempo de conhecimento do diagnóstico variou de menos de um ano a 14 anos $(M=4,1 ; D P=3,17)$. Os valores da contagem dos linfócitos T CD4 (número de células por milímetro cúbico de sangue), indicadores das condições do sistema imunológico, variaram de 2 a $1.728(M=409,3 ; D P=277)$. A carga viral plasmática, medida pela quantidade de cópias virais por mililitro $(\mathrm{ml})$ de sangue periférico, variou de 80 cópias $/ \mathrm{ml}$ até 2.350 .000 cópias $(M=51.694$; $D P=188.069,7)$. Quase um terço $(28,2 \%)$ dos participantes estava com carga viral indetectável (menor ou igual a 80 cópias $/ \mathrm{ml}$ ), indicador de alta eficácia do tratamento anti-retroviral.

Duzentos e oito participantes $(86,3 \%)$ relataram uso de medicamentos anti-retrovirais (ARV), sendo 
93,5\% deles sintomáticos e 69,4\% assintomáticos. A maioria dos pacientes $(72,9 \%)$ avaliou sua adesão como muito boa. No entanto, 85 pessoas $(38,8 \%)$ informaram ter interrompido o tratamento com ARV por conta própria em momentos anteriores, por motivos diversos, o que pode indicar rupturas ou falhas na adesão ao tratamento anti-retroviral.

\section{Instrumentos}

Os instrumentos utilizados foram questionários sociodemográfico e médico-clínico, roteiros de entrevista estruturados, elaborados para o estudo, com questões sobre sexo, idade, escolaridade, situação conjugal, situação empregatícia, ano de conhecimento do diagnóstico, número de internações anteriores associadas ao HIV, presença de sintomas e/ou doenças infecciosas oportunistas anteriores ou atuais; uso de terapia anti-retroviral; interrupção por conta própria do uso de anti-retrovirais; auto-avaliação da adesão ao tratamento anti-retroviral e orientação sexual. O questionário foi pré-testado em 10 pacientes, com condição sociodemográfica diversificada, para adequação quanto à linguagem e sequiência dos itens.

A variável condição clínica foi operacionalizada a partir das informações fornecidas pelos pacientes sobre a presença de sintomas da aids e/ou de infecções oportunistas atuais e/ou anteriores e internações anteriores devido à enfermidade, o que permitiu a classificação dos participantes em duas condições de saúde: (1) assintomático ou portador do HIV, quando o paciente referia ainda não ter tido nenhum sinal ou sintoma referente à enfermidade; (2) sintomático ou doente de aids, quando o paciente referia ter tido pelo menos um dos sintomas relacionados à aids e/ou pelo menos uma infecção oportunista associada à síndrome (Oliveira, Mello e Silva, Atomyla, Bonasser Filho \& Geraldes, 1996).

Escala Modos de Enfrentamento de Problemas (EMEP). Foi utilizado o instrumento de Seidl, Tróccoli e Zannon (2001), construído a partir do de Vitaliano, Russo, Carr, Maiuro e Becker (1985), na versão adaptada para o português por Gimenes e Queiroz (1997). A EMEP contém 45 itens, distribuídos em quatro fatores: enfrentamento focalizado no problema (18 itens, $\alpha=0,84$ ); enfrentamento focalizado na emoção (15 itens, $\alpha=$ $0,81$ ); busca de práticas religiosas (7 itens, $\alpha=0,74)$ e busca de suporte social (5 itens, $\alpha=0,70$ ). As respostas são dadas em escala Likert de cinco pontos ( 1 = Eu nunca faço isso; $5=\mathrm{Eu}$ faço isso sempre). Os escores variam de 1 a 5; os mais elevados indicam maior utilização de determinada estratégia de enfrentamento. No final do instrumento foi incluída questão aberta, de resposta opcional, indagando "Você tem feito alguma outra coisa para enfrentar ou lidar com a soropositividade?". O objetivo foi identificar outras estratégias de enfrentamento que porventura estariam sendo utilizadas, não incluídas na EMEP.

Análise fatorial exploratória (principal axis factoring, rotação ortogonal, eigenvalues maiores que $2 ; \mathrm{KMO}=$ 0,798) da EMEP com a amostra de pessoas HIV+ desse estudo resultou em três fatores, ao invés dos quatro encontrados por Seidl, Tróccoli e Zannon (2001). Observou-se a fusão do Fator 1 (focalizado no problema) com o Fator 4 (busca de suporte social); alguns itens cuja carga fatorial foi inferior a 0,30 foram excluídos. A solução fatorial verificada nessa amostra específica, semelhante à original, foi a seguinte: (1) enfrentamento focalizado no problema (14 itens; $\alpha=0,83) \quad-$ estratégias comportamentais de focalização no estressor voltadas para o seu manejo, como busca de suporte social, e estratégias cognitivas direcionadas para a reavaliação e ressignificação do problema; (2) enfrentamento focalizado na emoção (14 itens; $\alpha=0,80)$ - estratégias cognitivas e comportamentais de esquiva, negação, expressão de emoções negativas, autoculpa e/ou culpabilização de outros, com função paliativa ou de afastamento do problema; (3) busca de práticas religiosas (5 itens; $\alpha=0,68)$ - comportamentos e pensamentos religiosos como modos de enfrentamento e manejo do estressor. Optou-se por considerar essa solução fatorial nas análises subseqüentes do presente estudo, tendo-se em vista os bons indicadores quanto à confiabilidade e às qualidades psicométricas da EMEP para mensurar as estratégias de enfrentamento em pessoas vivendo com HIV/aids.

\section{Procedimento}

Os participantes foram convidados em dias de consulta médica ou quando estavam realizando algum procedimento (exames laboratoriais, outras modalidades de consulta) na unidade de saúde, constituindo amostra de conveniência. A resposta aos instrumentos, após assinatura do Termo de Consentimento Livre e Esclarecido, ocorreu em dia e horário agendados, no serviço de saúde a que o paciente estava vinculado. Aplicação individual assistida foi utilizada para os questionários sociodemográfico e médico-clínico; para a EMEP foi utilizado procedimento de resposta sem a presença do pesquisador, após orientação sobre a forma de preenchimento.

Estudos dessa natureza podem explicitar demandas de atendimento que aparecem no momento da coleta de dados. Foram disponibilizadas informações, orientação e referência para atendimento médico, psicológico e/ou social em serviço qualificado, quando necessário. 


\section{Análise de dados}

Inicialmente, foram realizados procedimentos para análise exploratória de dados visando identificar eventuais omissões de respostas, casos extremos univariados e multivariados, presença de singularidade e multicolinearidade entre as variáveis, que não foram identificados. Posteriormente, foi realizada análise fatorial exploratória da Escala Modos de Enfrentamento de Problemas (EMEP), para investigação da estrutura fatorial na amostra específica. Em seguida, procedeu-se às análises estatísticas descritivas, com a realização de testes bivariados (correlação de Pearson, teste $t$ de Student e qui-quadrado) para verificação de associações entre as variáveis do estudo.

As respostas à questão aberta sobre enfrentamento foram analisadas quanto aos temas, categorias e subcategorias identificados, com base em recursos metodológicos sugeridos por Bardin (1979) para análise de conteúdo.

\section{RESULTADOS}

Os resultados mostraram a variabilidade das estratégias de enfrentamento utilizadas, com distribuição satisfatória na amostra. As médias do enfrentamento focalizado no problema e de busca de práticas religiosas foram mais elevadas, indicando maior utilização dessas duas modalidades de estratégia pelos participantes. Observou-se, ainda, maior variabilidade de busca de práticas religiosas, indicada pelos valores do desvio-padrão e da amplitude. Os resultados das estratégias focalizadas na emoção quanto à média, moda e mediana mostraram que os participantes referiram sua utilização em menor freqüência. Esses resultados estão apresentados na Tabela 1.

Tabela 1. Análises descritivas das estratégias de enfrentamento medidas pela $\operatorname{EMEP}(N=241)$

\begin{tabular}{lcccccccc}
\hline Enfrentamento & Média & $\boldsymbol{D P}$ & Moda & \multicolumn{6}{c}{ Mdn } & Simetria Curtose Amplitude \\
\hline $\begin{array}{l}\text { Focalizado no } \\
\text { problema }\end{array}$ & 3,47 & 0,68 & 3,50 & 3,50 & $-0,28$ & $-0,55$ & $1,86-4,86$ \\
$\begin{array}{l}\text { Focalizado na } \\
\text { emoção }\end{array}$ & 2,17 & 0,66 & 2,36 & 2,14 & 0,34 & $-0,60$ & $1,0-3,86$ \\
$\begin{array}{l}\text { Busca de práticas } \\
\text { religiosas }\end{array}$ & 3,61 & 0,90 & 4,0 & 3,80 & $-0,44$ & $-0,49$ & $1,0-5,0$ \\
\end{tabular}

Nota: Escores variam de 1 a 5

Investigou-se a associação entre as estratégias avaliadas mediante análise de correlação de Pearson. Evidenciou-se correlação negativa discreta entre 0 enfrentamento focalizado no problema e o focalizado na emoção $(r=-0,13 ; p<0,05)$, indicando que, de modo geral, escores elevados no primeiro estiveram associados a escores baixos no segundo, apontando relativa incompatibilidade desses dois tipos de estratégia. Assim, enfrentamento ativo, voltado para o manejo da situação e para uma nova maneira de perceber o problema, pareceu se contrapor ao enfrentamento focalizado na emoção. Busca de práticas religiosas correlacionou-se positivamente, de forma discreta, com o enfrentamento focalizado no problema $(r=0,26 ; p<0,001)$ e com o focalizado na emoção $(r=0,16 ; p<0,01)$, o que leva à conclusão de que essa modalidade de enfrentamento ocorreu simultaneamente às demais, na amostra estudada.

\section{Estratégias de enfrentamento e variáveis sociodemo- gráficas e da condição clínica}

Testes $t$ exploraram diferenças segundo o sexo, escolaridade e situação conjugal para as três modalidades de enfrentamento (Tabela 2). Não foram observadas diferenças nas médias dos escores do enfrentamento focalizado no problema em relação a essas variáveis. No que concerne ao enfrentamento focalizado na emoção, observou-se diferença nas médias quanto ao sexo e quanto à escolaridade: mulheres e pessoas com menos escolaridade obtiveram médias mais elevadas, indicando uso mais freqüente desse tipo de enfrentamento.

Tabela 2. Médias e desvio-padrão das estratégias de enfrentamento segundo o sexo, escolaridade e situação conjugal $(N=241)$

\begin{tabular}{llccc}
\hline Enfrentamento focalizado no problema & $\boldsymbol{M}$ & $\boldsymbol{D P}$ & $\boldsymbol{t}$ \\
\hline Sexo & Homens & 3,48 & 0,69 & $-0,93$ \\
& Mulheres & 3,52 & 0,65 & \\
Escolaridade & $\leq$ Ensino médio incompleto & 3,39 & 0,67 & $-1,48$ \\
& $\geq$ Ensino médio completo & 3,52 & 0,68 & \\
Situação conjugal & Vive com parceiro/a & 3,46 & 0,71 & $-0,45$ \\
& Vive sem parceiro/a & 3,47 & 0,66 & \\
\hline Enfrentamento focalizado na emoção & & & \\
\hline Sexo & Homens & 2,11 & 0,62 & \multirow{2}{*}{$-2,01^{*}$} \\
& Mulheres & 2,29 & 0,70 & \\
Escolaridade & $\leq$ Ensino médio incompleto & 2,33 & 0,67 & $3,33 * *$ \\
& $\geq$ Ensino médio completo & 2,04 & 0,70 & \\
Situação conjugal & Vive com parceiro/a & 2,08 & 0,63 & $-1,12$ \\
& Vive sem perceiro/a & 2,23 & 0,67 & \\
\hline Busca de práticas religiosas & & & \\
\hline Sexo & Homens & 3,47 & 0,93 & $-3,76^{* *}$ \\
& Mulheres & 3,89 & 0,78 & \\
Escolaridade & $\leq$ Ensino médio incompleto & 3,76 & 0,83 & $2,32^{*}$ \\
& $\geq$ Ensino médio completo & 3,49 & 0,94 & \\
Situação conjugal & Vive com parceiro/a & 3,56 & 0,90 & \multirow{2}{*}{1,45} \\
& Vive sem parceiro/a & 3,65 & 0,90 & \\
\hline
\end{tabular}

$* p \leq 0,05 \quad * * p \leq 0,001$ 
Quanto à busca de práticas religiosas, foi observado resultado semelhante ao enfrentamento focalizado na emoção: mulheres e pessoas com escolaridade até o ensino médio incompleto também apresentaram médias mais elevadas, estatisticamente significativas, demonstrando maior utilização de busca de práticas religiosas como enfrentamento.

Investigou-se ainda a existência de diferenças nas médias das estratégias de enfrentamento segundo a condição clínica. Não foram verificadas diferenças significativas comparando-se os escores médios de pessoas sintomáticas e assintomáticas em relação ao enfrentamento focalizado no problema $(t=1,49 ; \quad p=0,13)$, focalizado na emoção $(t=-1,48 ; p=0,14)$ e busca de práticas religiosas $(t=-0,93 ; p=0,35)$.

\section{Outras estratégias de enfrentamento mencionadas pelos participantes}

Com base nas respostas dadas à questão aberta sobre outras estratégias de enfrentamento que as pessoas estariam utilizando para lidar com a soropositividade, verificou-se a presença de cinco categorias. Do total de participantes, $67,3 \%$ responderam a essa questão. As cinco categorias encontradas foram: (1) enfrentamento focalizado no problema, que abrangeu oito subcategorias; (2) normalização, entendida como viver independentemente do HIV, assumindo papéis sociais e a construção de projetos de vida; (3) distração, como busca de atividades prazerosas, de diversão e lazer; (4) busca de prática religiosa; (5) enfrentamento focalizado na emoção, com três subcategorias. A Tabela 3 apresenta esses achados, exemplificados com trechos de relatos dos participantes.

Tabela 3. Categorias e sub-categorias das estratégias de enfrentamento obtidas nos relatos dos participantes $(n=163)$

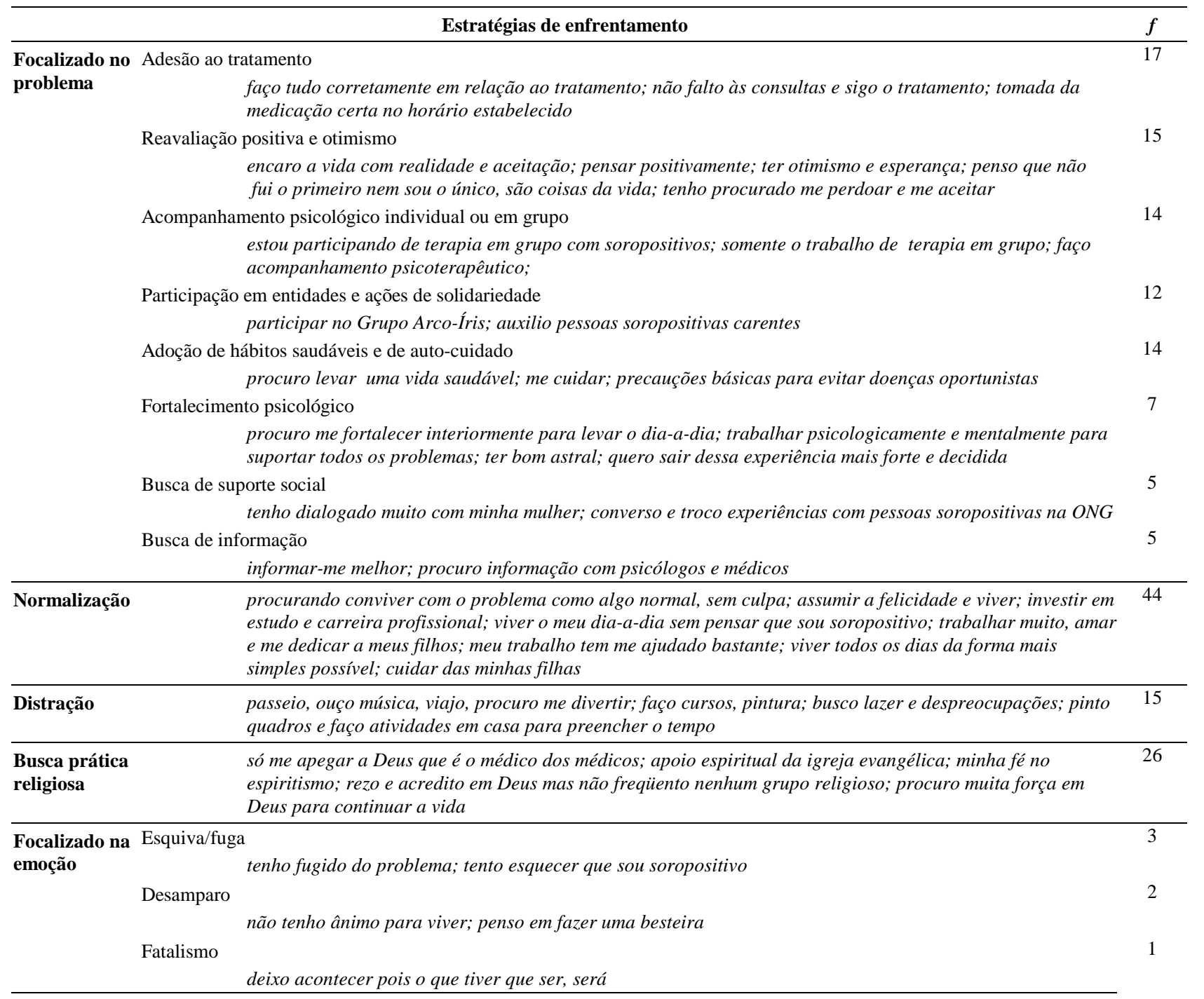




\section{DISCUSSÃO}

A caracterização sociodemográfica da amostra refletiu a tendência epidemiológica da doença no país. A proporção de dois homens para uma mulher, encontrada entre os participantes, é a que tem caracterizado a incidência de aids no Brasil e no Distrito Federal nos últimos anos, fenômeno denominado feminização, decorrente do aumento da transmissão heterossexual do HIV (Ministério da Saúde, 2003).

A caracterização médico-clínica referiu-se a pessoas em tratamento, vinculadas a unidades de saúde, a grande maioria usufruindo a terapia antiretroviral combinada. Este contexto parece ser responsável pelos bons indicadores identificados na maioria da amostra, tais como os níveis satisfatórios das taxas de linfócitos T CD4 e a proporção de participantes com carga viral indetectável. Pode-se afirmar que a caracterização observada é fruto do acesso ao tratamento e do acompanhamento por equipes de saúde em unidades públicas de referência.

A constatação de que os participantes utilizavam mais estratégias cognitivas e comportamentais focalizadas no problema e menos estratégias focalizadas na emoção vem ao encontro dos achados de estudos em HIV/aids (Singh, Berman, Swindells, Justis, Mohr, Squier \& Wagener, 1999) e de outros com amostras da população geral (Endler \& Parker, 1999; Seidl \& cols., 2001). A associação negativa entre essas duas modalidades era um resultado esperado, indicador de alguma incompatibilidade entre estas estratégias de enfrentamento, também verificado por Endler e Parker (1999), com amostras de pessoas adultas da população geral, utilizando o Coping Inventory for Stressful Situations, cujas subescalas enfrentamento orientado para a tarefa e enfrentamento orientado na emoção - apresentam conteúdos semelhantes aos dois fatores da EMEP.

Quanto ao enfrentamento na emoção, é possível observar que a maior utilização dessa estratégia é um indicativo da presença de dificuldades emocionais associadas à soropositividade. Os conteúdos dos itens da EMEP, que mensuraram essa modalidade de enfrentamento, expressam sentimentos de culpa em relação a si próprio e ao outro, emoções negativas e comportamento de esquiva, o que leva a supor que escores mais elevados seriam sugestivos de dificuldades psicológicas relevantes. Achados nessa direção foram encontrados por pesquisadores que utilizaram outras medidas de enfrentamento: enfrentamento focalizado na emoção ou de esquiva esteve associado à depressão em estudos com pessoas soropositivas (Fleishman \& Fogel, 1994; Schmitz \& Crystal, 2000).

Outro achado do presente estudo refere-se ao uso mais freqüente do enfrentamento focalizado na emoção por pessoas com menos escolaridade e por mulheres. Este resultado parece resultar da influência de dificuldades relativas à condição socioeconômica e de gênero, que, somadas às adversidades da condição clínica, poderiam resultar em um número maior de estressores, com repercussão negativa sobre o bemestar psicológico (Sowell, Seals, Moneyham, Demi, Cohen \& Brake, 1997). Evidências dessa natureza têm sido observadas cotidianamente na prática clínica, no atendimento a pessoas soropositivas (Seidl \& cols., no prelo).

Observou-se que as respostas dadas à questão aberta complementaram aquelas obtidas com a aplicação da EMEP, embora nem sempre representassem novas estratégias. Isso se verificou apenas em relação à normalização e à distração, o que possibilitou o aparecimento de modos de lidar com a soropositividade que não eram abarcados pelo instrumento utilizado. Denominou-se normalização a atitude de focalizar a vida dando continuidade aos projetos e ao desempenho de papéis sociais no âmbito da família e do trabalho. A normalização representa uma estratégia diante de situações como enfermidades crônicas, sem cura e eventualmente estigmatizantes, que podem "tirar da normalidade", afetando o bemestar psicológico, o desempenho de papéis sociais e a concretização de projetos de vida. Ressalte-se, no entanto, que o uso dessa modalidade de enfrentamento parece estar sendo factível pelo êxito do tratamento: o retorno à normalidade viabiliza-se pela melhoria do estado de saúde para os sintomáticos e manutenção de bom estado de saúde para os assintomáticos, aspectos da enfermidade em tempos da terapia anti-retroviral combinada (Dunbar, Mueller, Medina \& Wolf, 1998).

Outra modalidade de enfrentamento referida foi distração, que tem sido valorizada por alguns estudiosos (Endler \& Parker, 1999). O manejo do estresse em situações que demandam esforços adaptativos vem sendo trabalhado por psicólogos que atuam com base no enfoque cognitivo-comportamental (Schneiderman, Antoni, Saab \& Ironson, 2001), com técnicas diversas como relaxamento, distração, entre outras.

Sobre a importância da religiosidade como estratégia para lidar com a enfermidade, esta foi evidenciada em diversas respostas dos participantes, achados semelhantes aos encontrados no estudo com amostra não soropositiva, realizado por Seidl e cols. (2001), quando se observou que mulheres e pessoas 
com menos escolaridade utilizavam mais busca de práticas religiosas como estratégia de enfrentamento para lidar com estressores. No presente estudo, busca de práticas religiosas esteve associada positivamente tanto com enfrentamento no problema quanto com enfrentamento na emoção. No primeiro caso, supõe-se que a religiosidade estaria relacionada a estratégias de aproximação e de manejo do problema; no segundo, busca de práticas religiosas poderia funcionar como justificativa para a esquiva da situação e/ou para a adoção de idéias fatalistas, atribuindo a forças externas (um ser divino) o aparecimento e a resolução do problema. Pesquisas têm investigado a função das práticas e crenças religiosas no ajustamento em relação à soropositividade (Barroso, 1997; Biggar, Forehand, Devine, Brody, Armistead, Morse \& Simon, 1999). Destaca-se a necessidade de estudos que elucidem melhor o papel da religiosidade em situação de enfermidade crônica, principalmente devido ao significado das tradições religiosas na sociedade contemporânea e, em particular, na sociedade brasileira (Faria, 2004).

É possível concluir que a EMEP, como medida do enfrentamento, talvez não tenha sido suficiente para captar especificidades do enfrentamento no contexto da soropositividade. Por outro lado, seus resultados são consistentes com achados da literatura em HIV/aids, indicando ainda coerência teórica com o modelo interativo do estresse de Lazarus e Folkman (1984). A inclusão de questões abertas suplementares ao final do instrumento padronizado permitiu a expressão de temas eventualmente não abordados no mesmo. No futuro, a inclusão de outros itens e a constituição de novos fatores, seguidas de nova análise de sua estrutura fatorial, podem aprimorar a EMEP, ampliando o espectro das estratégias de enfrentamento contempladas pela escala.

Algumas limitações em relação ao construto enfrentamento merecem ser retomadas e consideradas em estudos futuros. A noção de avaliação cognitiva (appraisal) da situação estressante, responsável pela flexibilidade e pela diversidade das estratégias/respostas de enfrentamento (Folkman, Lazarus, Gruen \& De Longis, 1986), torna desafiador o empreendimento de construção de uma escala de modos de enfrentamento. Nesse sentido, a possibilidade dos relatos verbais dos participantes, dada pela questão aberta, permitiu conhecer outras estratégias que vinham sendo utilizadas, reforçando a validade e os aspectos positivos do instrumento, mas apontando também as suas deficiências.

Nesse sentido, é válido reforçar a importância da complementação de metodologias - quantitativas e qualitativas - permitindo a melhor compreensão de fenômenos psicológicos, como o enfrentamento. Conclui-se, assim, que pesquisas futuras nesse campo devem dar continuidade aos cuidados metodológicos recomendados por Endler e Parker (1999) e Lazarus (2000), assim como diversificar as metodologias utilizadas, desenvolvendo também estudos qualitativos. Considera-se que o aporte de metodologias diferentes é necessário, no sentido de permitir diferentes aproximações em relação ao objeto de estudo, favorecendo a prática profissional e a produção de conhecimento em psicologia da saúde.

\section{REFERÊNCIAS}

Antoniazzi, A. S., Dell' Aglio, D. D. \& Bandeira, D. R. (1998). O conceito de coping: uma revisão teórica. Estudos de Psicologia, 3, 273-294.

Bardin, L. (1979). Análise de conteúdo. Lisboa: Edições 70.

Barroso, J. (1997). Reconstructing my life: Becoming a longterm survivor of AIDS. Qualitative Health Research, 7, 57-74.

Biggar, H., Forehand, R., Devine, D., Brody,G., Armistead, L., Morse, E. \& Simon, P. (1999). Women who are HIV infected: the role of religious activity in psychosocial adjustment. Aids Care, 11, 195-199.

Dunbar, H. T., Mueller, C. W., Medina, C. \& Wolf, T. (1998). Psychological and spiritual growth in women living with HIV. Social Work, 43, 144-154.

Endler, N. S. \& Parker, J. D. A. (1999). Coping inventory for stressful situations (CISS). Manual Second Edition. Toronto: Multi-Health Systems Inc.

Faria, J. B. (2004). Religiosidade, enfrentamento e bem-estar subjetivo em pessoas vivendo com HIV/aids. Dissertação de Mestrado Não- Publicada, Universidade de Brasília.

Fleishman, J. A. \& Fogel, B. (1994). Coping and depressive symptons among people with AIDS. Health Psychology, 13, 156-169.

Folkman, S., Lazarus, R. S., Gruen, R. J. \& De Longis, A. (1986). Appraisal, coping, health status and psychological symptons. Journal of Personality and Social Psychology, 50, 571-579.

Folkman, S. \& Moskowitz, J. T. (2000). Positive affect and the other side of coping. American Psychologist, 55, 647-654.

Gimenes, M. M. G. \& Queiroz, B. (1997). As diferentes fases de enfrentamento durante o primeiro ano após a mastectomia. Em M.G.G. Gimenes \& M.H. Fávero (Orgs), A mulher $e o$ câncer (pp. 171-195). Campinas: Psy.

Hobfall, S. E. (2002). Social and psychological resources and adaptation. Review of General Psychology, 6, 307-324.

Kelly, J. A, Otto-Salaj, L. L., Sikkema, K. J., Pinkerton, S. D. \& Bloom, F. R. (1998). Implications of HIV treatment advances for behavioral research on AIDS: Protease inhibitors and new chalenges in HIV secondary prevention. Health Psychology, 17, 310-319.

Lazarus, R. S. \& Folkman, S. (1984). Stress, appraisal and coping. New York: Springer Publishing Co. 
Lazarus, R. S. (2000). Toward better research on stress and coping. American Psychologist, 55, 665-673.

Leserman, J., Perkins, D. O. \& Evans, D. L. (1992). Coping with the threat of AIDS: The role of social support. American Journal of Psychiatry, 149, 1514-1520.

Ministério da Saúde. Programa Nacional de DST e Aids (2003). Aids - Boletim Epidemiológico. Ano XVII no $01-1^{\mathrm{a}} \mathrm{a}$ $52^{\mathrm{a}}$ semanas epidemiológicas.

Oliveira, M. S., Mello e Silva, A. C. C., Atomyla, A. N., Bonasser Filho, F. \& Geraldes, S. M. (1996). Aspectos clínicos e tratamentos específicos. Em A. L. M. Lima, C. R. Kiffer \& D. Uip (Orgs.), HIV/aids: perguntas e respostas (pp. 93-126). São Paulo: Livraria Atheneu.

Schmitz, M. F. \& Crystal, S. (2000). Social relations, coping, and psychological distress among persons with HIV/AIDS. Journal of Applied Social Psychology, 30, 665-685.

Schneiderman, N., Antoni, M. N., Saab, P. G. \& Ironson, G. (2001). Health psychology: Psychosocial and biobehavioral aspects of chronic disease management. Annual Review Psychology, 52, 555-580.

Seidl, E. M. F.; Tróccoli, B. T. \& Zannon, C. M. L. C. (2001). Análise fatorial de uma medida de estratégias de enfrentamento. Psicologia: Teoria e Pesquisa, 17, 225-234.

Seidl, E. M. F., Zannon, C. M. L. C \& Tróccoli, B. T. (no prelo). Qualidade de vida, enfrentamento e suporte social em pessoas vivendo com HIV/aids. Psicologia Reflexão e Crítica.
Singh, N., Berman, S. M., Swindells, S., Justis, J. C., Mohr, J. A., Squier, C. \& Wagener, M. M. (1999). Adherence of Human Immunodeficiency Virus-Infected patients to antiretroviral therapy. Clinical Infectious Diseases, 29, 824-830.

Somerfield, M. R \& McCrae, R. R. (2000). Stress and coping research. Methodological challenges, theoretical advances and clinical aplications. American Psychologist, 55, 620-625.

Sowell, R. L., Seals, B. F., Moneyham, L., Demi, A., Cohen, L. \& Brake, S. (1997). Quality of life in infected women in the south-eastern United States. AIDS Care, 9, 501-512.

Thoits, P. A. (1995). Stress, coping and social support processes: Where are we? What next? Journal of Health and Social Behavior, Extra Issue, 53-79.

Vitaliano, P. P., Russo, J., Carr, J. E., Maiuro, R. D. \& Becker, J. (1985). The Ways of Coping Checklist: Revision and psychometric properties. Multivariate Behavioral Research, 20, 3-26.

Wu, A. W. (2000). Quality of life assessment comes of age in the era of highly active antiretroviral therapy. Aids, 14, 14491451.

Recebido em 24/02/2005 Aceito em 30/08/2005
Endereço para correspondência: 